\title{
Active Power Management in a Low-voltage Islanded Microgrid
}

\author{
M. A. Hossain*1, H. R. Pota ${ }^{1}$, M. J. Hossain ${ }^{2}$, and A. M. O. Haruni ${ }^{1}$ \\ ${ }^{1}$ School of Engineering $\& 3$ Information Technology, The University of New South Wales, \\ Canberra, ACT 2610, Australia \\ ${ }^{2}$ Department of Engineering, Macquarie University, Sydney, NSW-2109, Australia
}

\begin{abstract}
The growing electricity demand and scarcity of energy sources are the driving force of exploration of the renewable energy sources. However, uncertain energy production of these sources makes difficulties in their control and operation with or without a grid utility connection. This paper proposes a novel power control strategy which employs a voltage band in the DC-link voltage to maintain voltage stability and thereby improve the power quality during temporary disturbances in a network. It is applied to act as an inverter's inertia and obtain maximum benefit from the storage system, based on the features of a DC busbar to avoid a voltage limit violation. It also presents a demand dispatch strategy based on a client's terminal voltage, which avoids the complexity of communication lines, for balancing the network power during power shortages. The developed control algorithm is tested on an IEEE 16 bus test feeder with multiple DG units and from the results it is found that the proposed control methods provide effective control of the voltage and power quality during transient conditions and scarce power generation.
\end{abstract}

Keywords: DC-link energy, islanded microgrid, balanced power, stable voltage, voltage-band.

\section{Introduction}

Due to increased concern about energy crisis and environmental issues, the power industry is shifting their power production from conventional power sources to re-

\footnotetext{
*Corresponding author

Email address: Md.Hossain6@student.adfa.edu.au (M. A. Hossain*)
} 
newable energy sources (RESs). The power industry is incorporating RESs into the 5 grid utility in the form of distributed generations (DGs). The application of DGs can enhance reliability and stability of the local network, and can reach benefits to the suppliers by reducing system losses and investment on a new transmission line due to increased power consumption [1, 2, 3]. Power generation in the form of DGs for local and grid utility can create issues as many as it may solve. Therefore, a microgrid concept is evolved to coordinate among sources, loads, and energy storage devices for maintaining a distribution network stability [4, 5]. A microgrid can be considered as a controlled small-scale power network's system, consisting of small-scale emerging generators, loads, energy storage elements, and control units, built within a defined area for maintaining system stability, reliability, and facilitating improved power quality to the consumer's premises [6]. During autonomous operation, microgrid elements, such as voltage source converters (VSCs), are principally responsible for providing voltage and frequency set points within a distribution network.

In a microgrid, small-scale emerging generators such as wind, solar, fuel cell, and small-scale gas turbine, are installed in proximity to the load side, and use inverters as interface devices to inject active and reactive power into the network [7, 8]. Inverters are able to supply controlled voltage and frequency depending on the control algorithms [9]. The characteristics of inverters are significantly different from the conventional generators; therefore, specific control algorithms are required for a stable microgrid operation [10, 11, 12, 13].

There are several literatures that propose droop-based control for facilitating high reliability and avoiding the complexity of communication lines [14, 15, 16, 17]. Droop control is popular due to its capability to coordinate various power rating units as well as being flexible and reliable, and is valid for both high-voltage (HV) transmission lines and low-voltage (LV) distribution ones. In an LV distribution network, the well-known active power/frequency (P/f) droop control requires much more effort than the active power/voltage $(\mathrm{P} / \mathrm{V})$ one because a predominantly resistive network naturally connects active power to the grid voltage [18, 19, 20, 21, 22, 23]. For this reason, to control the voltage magnitude and network frequency in an LV microgrid, 
both $\mathrm{P} / \mathrm{V}$ and reactive power/frequency $(\mathrm{Q} / \mathrm{f})$ droop controls are adopted.

As the application of control algorithms in stead of the straightforward employment of droop control in a microgrid needs to be reviewed due to the increasing penetration of intermittent RESs, considering the renewable energy features mentioned in [23], voltage-based droop (VBD) control is proposed. Such a control approach integrates intermittent RESs rather than dispatchable energy sources by applying delays in the power change points. In it, although the terminal voltage is changed proportionally to variations in the power demand, a terminal voltage deviation is not expected from a consumer perspective. Moreover, the active power control in [23] is postponed up to a certain limit of the terminal voltage considering the features of RESs. However, recently, RESs have been using energy storage elements [24], such as batteries, that can deliver power, as a dispatchable generator, into the network during a power mismanagement. Therefore, the VBD method needs to be modified for application in microgrids.

This paper proposes a control algorithm for minimising changes in consumers terminal voltage while facilitating steady-state power consumption during any small transient event. This strategy enables any unpredictable supply and demand to be balanced within tolerable DC-link voltages $\left(V_{d c}\right)$ considering random power/load fluctuations. The proposed control strategy enables balancing unpredictable supply and demand within tolerable DC-link voltage $\left(V_{d c}\right)$.

To control the power supply and demand in a network, generally, the central energy management system (EMS) [25, 26, 27, 28, 29] needs to access each DG and load point for power measurements through communication lines. The design and modelling of these communication lines can be found in [30, 31]. The communication modules create a complicated network. This is because, if any DG or load point is out of the communication range, the EMS may produce an unexpected signal sufficient to incur an unusual situation. Therefore, using communication lines as a primary control strategy reduces the reliability of a microgrid [32]. However, it is always desirable to use the communication links for an optimal decision process in a tertiary control layer considering the electricity market and fuel cost [33].

The influence due to malfunctioning communication on demand response is anal- 
ysed, and an optimal resource allocation scheme depending on features of the both power demand and monitoring data transmissions is proposed to minimise the influence in [34]. In [35], an adaptive dynamic model is proposed to regulate voltage based on demand response strategy for reducing voltage fluctuation at customer premises in an LV distribution feeder. To prevent voltage and current limit violation in a distribution network considering fair consumer participation, a proactive centralised control for one hour ahead load and a reactive decentralised control for regulating consumption are presented in [36]. However, in the existing literatures, the concept of primary centralised load control for microgrids without communication is not found.

To improve the reliability of a microgrid, this paper also presents a demand-side management system without communication lines that depend on the terminal voltage of a consumer's premises which assists in providing greater microgrid reliability along with a secondary controller.

The major contributions of this paper are summarised as follows.

(1) A voltage band, which acts as inertia for an inverter's DC-link voltage controller to exploit the stored energy during disturbances and thereby minimise network voltage variations, is proposed. As it improves the quality of the network's voltage, the power quality of a microgrid is enhanced.

(2) A voltage controller of an inverter, avoiding cascaded PI controller tuning while minimising the cost function of the system, is designed to track the instantaneous reference grid voltage with nullifying steady state error during disturbances. The application of the proposed voltage controller in a natural (abc) frame avoids the complexity of the Clarke and Park transformation.

(3) A novel and simple demand-side management system based on the terminal voltages of end-users without communication lines is presented. The proposed strategy uses relay-based load curtailment at the connection points of controlled loads in the case of a power deficiency of DG units in a microgrid.

The rest of this paper is structured as follows. In Section 2, an overall control approach for inverters in a microgrid configuration is briefly discussed. Section 3 


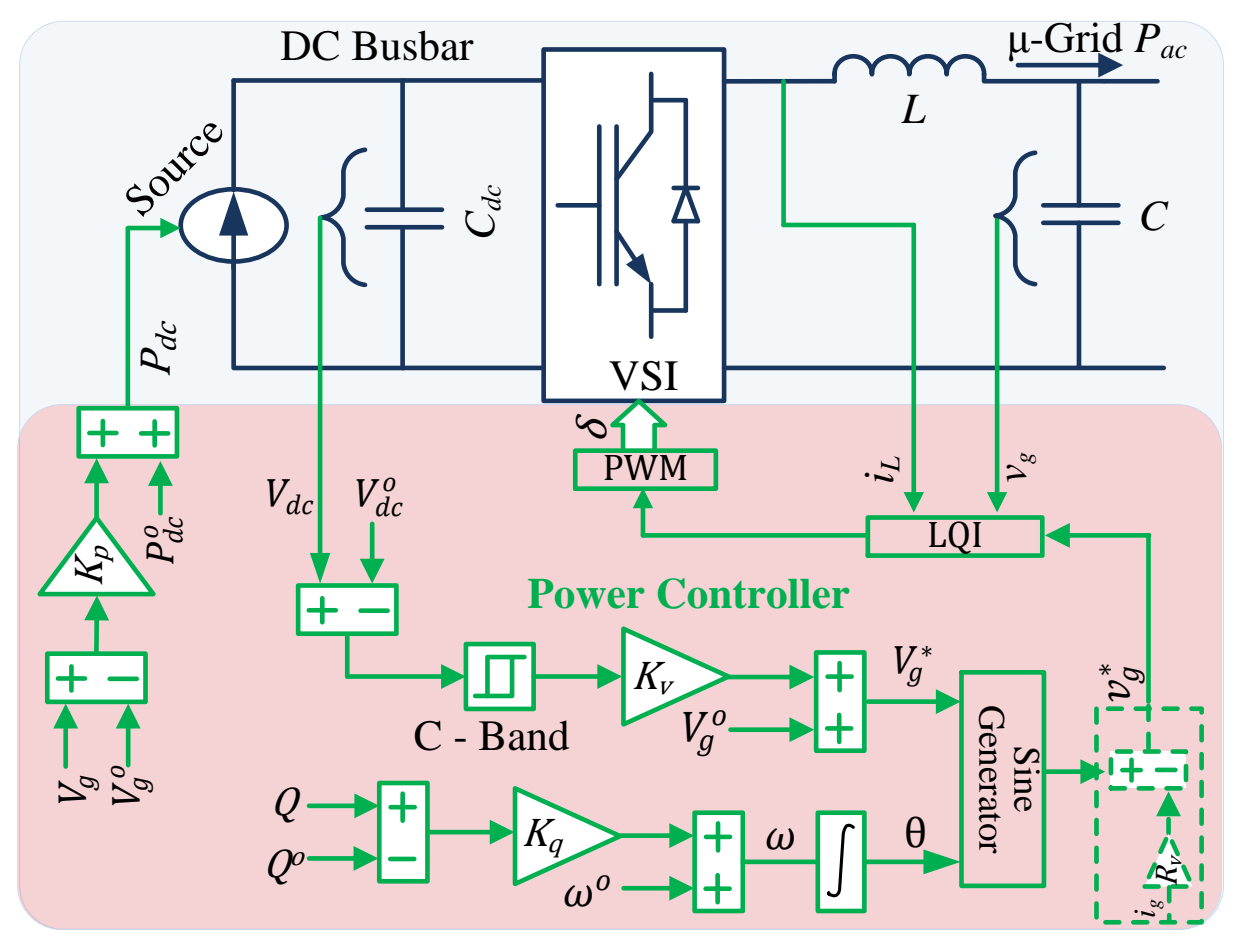

Figure 1: Microgrid's power control strategy.

describes the microgrid control algorithms for a predominantly resistive line and develops a voltage control strategy to track the reference grid voltage. In Section 4. the simulation results demonstrate the effectiveness of the proposed controller compared with that of the VBD controller in a simple network. Section 5 presents the proposed control strategies in advanced networks to evaluate their performances for balancing the power supply and demand in a distribution network.

\section{System Overview}

The proposed overall VBD control strategy for a microgrid is shown in Figure 1. The power supplied from an energy source is considered a controlled power source, the power flow of which is adjusted based on the terminal voltage profile. Most DG units are connected to a network through voltage source inverters (VSIs) which convert the voltage from DC to AC. As a VSI can supply controlled active and reactive powers to a network, only its control is assumed and analysed as a microgrid control. Inverter outputs are controlled by changing the pulse width modulations (PWMs) produced by the linear quadratic regulator with integrator (LQI) and VBD 
control algorithms while the source power is changed according to terminal voltage variations using a proportional controller. To attenuate the converted ripple waves, an LC filter is introduced after the VSI, and a capacitor applied at the DC busbar prevents the transient effect with the help of its energy. The dashed line block represents a virtual resistance loop that can be applied to the control loops for decoupling the powers and preventing oscillation, which may appear due to relatively low resistance in line for multiple DG units. A simple microgrid consists of a power source connected to branches of resistive loads with unpredictable levels of participation in a distribution network.

\section{Control Methods}

The VBD control algorithm enables inverters to control the power flow in a network while considering the characteristics of RESs without the help of the grid utility. The algorithms presented in this paper are extended work of authors' own in [37] and versions of that proposed in [23] modified in two main steps by: (1) using an LQI, instead of linear quadratic regulator (LQR), method for tracking the instantaneous reference grid voltage as it demonstrates better performance for eliminating the steady-state error produced by disturbances in a system; and (2) proposing a voltage band in the DC-link voltage control to optimally exploit the DC busbar's energy. The authors' work is extended by applying the control method in multi-machine microgrid system and proposing a demand-side management without communication lines.

\subsection{DC-link voltage control}

The relationship between the active power demand and DC-link voltage of an inverter is important for controlling the inverter's power supply in a microgrid. Variations in power demand alter the DC-link voltage $\left(V_{d c}\right)$ which can be used as an indicator of the power status in an inverter-connected generator. It is an analogous parameter of the conventional rotating machine, the frequency of which is used as a feedback signal to control the active power.

Therefore, as this grid voltage/DC-link voltage $\left(V_{g} / V_{d c}\right)$ control strategy is applied to control the terminal voltage, the power mismatch information available in 
the $V_{d c}$ changes the reference grid's voltage magnitude $\left(V_{g}^{*}\right)$ to balance the power supply and demand through the $P_{d c} / V_{g}$ control strategy shown in Figure 1 . The $V_{g} / V_{d c}$ control method is expressed by:

$$
V_{g}^{*}=V_{g}^{\circ}+K_{v}\left(V_{d c}-V_{d c}^{\circ}\right)
$$

where $K_{v}$ is a positive droop constant, and $V_{g}^{\circ}$ and $V_{d c}^{\circ}$ the set values of the grid and DC-link voltages, respectively. Generally, the value of $K_{v}$ can be determined from the formula $\frac{\Delta V_{g}}{\Delta V_{d c}}$, where $\Delta V_{g}$ is the grid voltage deviation and $\Delta V_{d c}$ is the DC-link voltage deviation. The droop control in (1) is modified by introducing a voltage-band, b Volt wide, as shown in Figures 2a and 3 . This width depends on the characteristics of generation sources, converter topologies, DC busbar, and types of microgrids. For instance, it can be large for getting a wider maximum power point tracking (MPPT) range of solar generators. In this way, a better performance can be achieved for photovoltaic (PV) power. On the other hand, it can be set small to maintain high power quality, such as a hospital, for operating sophisticated equipment used in a microgrid. Moreover, the width of the constant voltage-band can be adjusted in order to meet the specification of a particular microgrid for fully exploiting generation control abilities and avoid frequent voltage changes.

The reference grid voltage of VSIs is set as:

$$
V_{g}^{*}=\left\{\begin{array}{rr}
V_{g}^{\circ}+K_{v}\left\{V_{d c}-\left(V_{d c}^{\circ}+b\right)\right\} & \text { if } V_{d c}>V_{d c}^{\circ}+b \\
V_{g}^{\circ}+K_{v}\left\{V_{d c}-\left(V_{d c}^{\circ}-b\right)\right\} & \text { if } V_{d c}<V_{d c}^{\circ}-b \\
V_{g}^{\circ} & \text { if } V_{d c}^{\circ}-b \leq V_{d c} \leq V_{d c}^{\circ}+b .
\end{array}\right.
$$

It can be seen in Eq. (2) that the reference voltage is constant at its previous set value in the voltage band (b) $\mathrm{V}$ wide and that, changing the $V_{d c}$ values also changes those of the $V_{g}^{*}$ after a certain voltage range which assists in altering the power delivery to the network using the $P_{d c} / V_{g}$ droop control.

\subsection{Active power control}

The voltage limit may be violated by employing only the $V_{g} / V_{d c}$ droop control because the power flow cannot be completely controlled [23]. Therefore, a power 


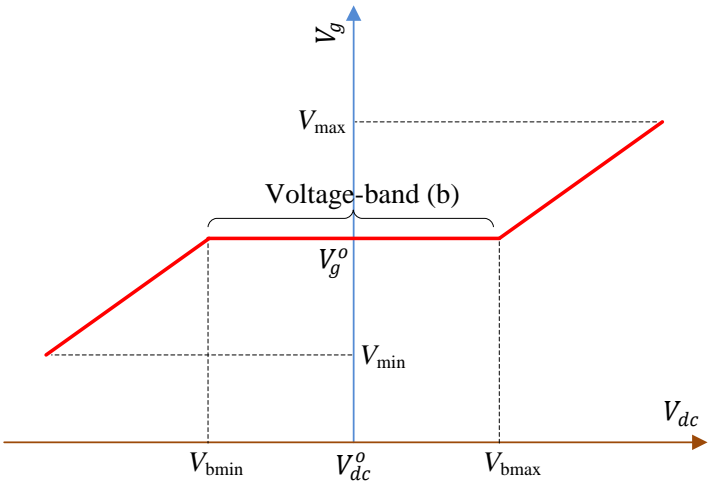

(a)

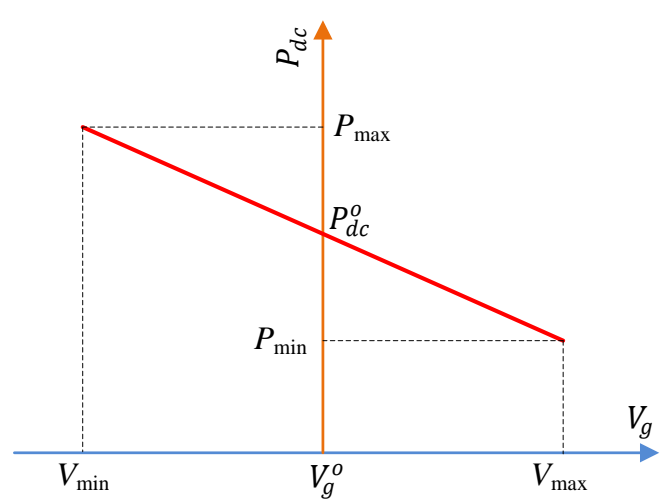

(b)

Figure 2: Graphical representations of (a) $V_{g} / V_{d c}$ droop control and (b) $P_{d c} / V_{g}$ droop control.

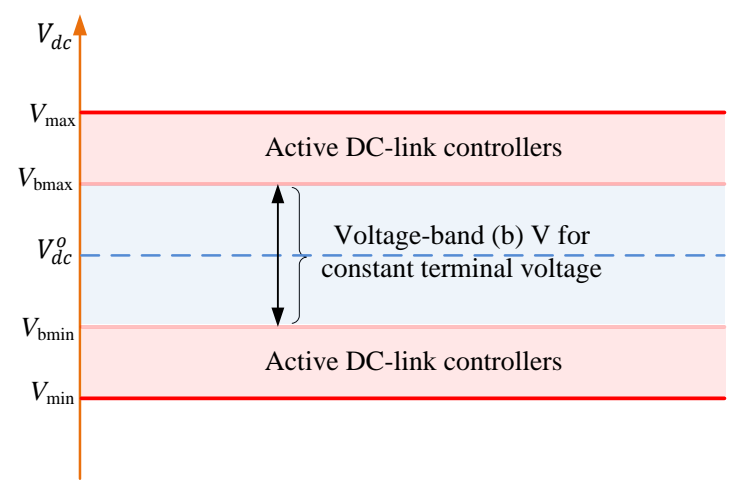

Figure 3: Proposed voltage-band in DC-link voltage control.

control approach based on the relationship between the source power $\left(P_{d c}\right)$ and DG terminal voltage $\left(V_{g}\right)$ is developed to supply power during voltage limit violations (Figure 2b). The supply from a DC power source $\left(P_{d c}\right)$ can be changed in several ways to control the terminal voltage: decreased by charging the battery, shifting the MPPT points for renewable sources or using a dumping load; and increased by discharging the battery or increasing the power generation for dispatchable sources. In this power control strategy, $P_{d c}$ can be expressed by:

$$
P_{d c}=P_{d c}^{\circ}+K_{p}\left(V_{g}-V_{g}^{\circ}\right)
$$

where $K_{p}$ is a negative droop constant, $P_{d c}$ depends on the terminal grid voltage and $P_{d c}^{\circ}$ indicates the set value of a generator synthesised according to the optimisation process of a management system. 


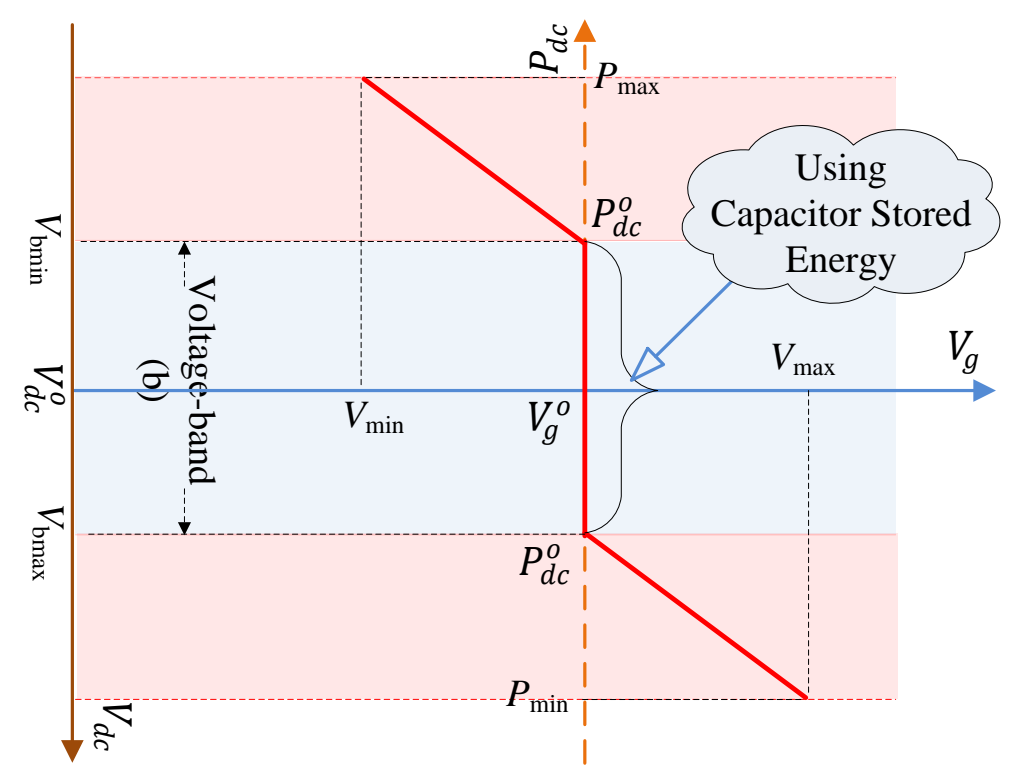

Figure 4: Combination of $V_{g} / V_{d c}$ and $P_{d c} / V_{g}$ droop controls.

\subsection{Combined control approach}

Applying both controllers (DC-link and power) can be more effective than using only the DC-link voltage controller which can violate the voltage limit in a network and create problems for controlling the power injection. The inter-relationships among the DC voltage, grid voltage and generator power are shown in Figure 4 by bringing two different figures on the same plane of $\mathrm{x}-\mathrm{y}$ axis for improved clarity. It can be seen that the decreasing $V_{d c}$ after the voltage band is supported by the increasing DG power supply and vice versa. In this approach, the power control strategy $\left(P_{d c} / V_{g}\right)$ is not activated in the balanced condition of a network although it works during a power mismatch between supply and demand. It is clear that the DC-link energy supports energy balance in a network during disturbances without severely affecting the grid voltage and maintaining it within the acceptable bandwidth range much like a mechanical inertia in the flat interval region due to the existence of the DC-link capacitor. This inertia is analogous to the inertia of a large rotating machine that assists in enhancing system stability by minimising dynamic/transient effects. Therefore, this voltage band improves the voltage profile and power quality by reducing voltage variations and exploiting the DC-link energy. 


\subsection{Reactive power control}

The power control of an LV microgrid with multiple generators is not possible by using a simple active power control algorithm as it is regulated by the network's

The modulation index/input of the PWM, which generates duty ratio of the VSI, is calculated by the LQI voltage controller to track the reference grid voltage.

where $K_{q}$ is a positive slope index, $Q^{\circ}$ the set value of the reactive power and the index "o" a predefined set value. With the increasing participation of inductive loads in a network, the frequencies of connected DG units will also increase owing to a positive $K_{q}$ value.

\subsection{Voltage controller design}

To control the grid voltage, an LQI, which minimises the cost function of the system, is employed to satisfy the fast dynamic response and abolish the steadystate voltage error between the instantaneous grid voltage $\left(v_{g}\right)$ and instantaneous reference grid voltage $\left(v_{g}^{*}\right)$ during load changes, with its integral term reducing errors between the command and desired signals. It demonstrates excellent performances in terms of changing the LC filter's parameters, noise-affected measured signals and sudden load changes. The primary reason for proposing this method is to easily determine the optimal gains that provide effective tracking with an almost zero steady-state error. The $V_{g}^{*}$ is determined using the $V_{g} / V_{d c}$ droop control strategy, and the design process of the voltage controller is described below. 
The state-space model for the considered system can be expressed as:

$$
\left[\begin{array}{l}
\dot{v}_{g} \\
\dot{i}_{L}
\end{array}\right]=\left[\begin{array}{cc}
0 & \frac{1}{C} \\
-\frac{1}{L} & 0
\end{array}\right]\left[\begin{array}{c}
v_{g} \\
i_{L}
\end{array}\right]+\left[\begin{array}{c}
0 \\
1 / L
\end{array}\right]\left[v_{s w}\right]+\left[\begin{array}{c}
-1 / C \\
0
\end{array}\right]\left[i_{g}\right]
$$

where $i_{L}$ and $v_{s w}=\delta V_{d c}$ are the instantaneous inductor current and the mean switching voltage over a PWM period, respectively. Here, $\delta=$ duty ratio, whose value varies in between $-1 \leq \delta \leq 1$. In this model, grid current $\left(i_{g}\right)$ variation is treated as a disturbance.

For the grid voltage control, $v_{g}$ is taken as an output parameter:

$$
\left[v_{g}\right]=\left[\begin{array}{ll}
1 & 0
\end{array}\right]\left[\begin{array}{l}
v_{g} \\
i_{L}
\end{array}\right]
$$

The general form of the state space Eqs. (5) and (6) is given below:

$$
\begin{aligned}
& \dot{x}=A x+B u \\
& y=C x+D u
\end{aligned}
$$

where

$x=\left[\begin{array}{c}v_{g} \\ i_{L}\end{array}\right] ; u=\left[v_{s w}\right] ; \quad A=\left[\begin{array}{cc}0 & \frac{1}{C} \\ -\frac{1}{L} & 0\end{array}\right] ; \quad B=\left[\begin{array}{c}0 \\ 1 / L\end{array}\right] ; \quad C=\left[\begin{array}{cc}1 & 0\end{array}\right] ;$ and $D=[0]$.

The disturbance term, $i_{g}$, is not included in Eq. (7) because its effect is negligible in voltage control, and the system can be controlled considering $v_{g}$ and $i_{L}$ as state vector.

The input vector of the microgrid system considering the integral action of the controller can be computed using the following formula:

$$
u^{\prime}=-K x+K_{i} \int_{0}^{\infty}\left(v_{g}^{*}-v_{g}\right) d t
$$

where $K_{i}$ is the integral gain used to minimise the error between $v_{g}^{*}$ and $v_{g} ; K$ is the gain obtained using the LQR optimisation method.

The error term requires a definition for solving the integral gain, $K_{i}$, value:

$$
e=\int_{0}^{\infty}\left(v_{g}^{*}-v_{g}\right) d t
$$


Differentiating Eq. (10) and substituting the value of $v_{g}=C x$; the above equation can be written:

$$
\dot{e}=v_{g}^{*}-C x \text {. }
$$

Rewriting the control law:

$$
u^{\prime}=-K x+K_{i} e
$$

Further reducing to

$$
u^{\prime}=-K^{\prime} x^{\prime}
$$

where $K^{\prime}=\left[\begin{array}{ll}K & -K_{i}\end{array}\right]$; and $x^{\prime}=\left[\begin{array}{ll}x & e\end{array}\right]$.

The modified state space equations can be written as:

$$
\begin{aligned}
& \dot{x}=A^{\prime} x^{\prime}+B^{\prime} u^{\prime} \\
& y=C^{\prime} x^{\prime}
\end{aligned}
$$

where $A^{\prime}=\left[\begin{array}{lll}A & 0 ;-C & 0\end{array}\right] ; B^{\prime}=[B ; 0] ;$ and $C^{\prime}=\left[\begin{array}{ll}C & 0\end{array}\right]$.

The solution of $K^{\prime}$ in Eq. (13) should converses the error produced by disturbances to zero, provided there are a stable system and minimisation of the cost function:

$$
J^{\prime}=\int_{0}^{\infty}\left(x^{\prime T} Q x^{\prime}+u^{\prime T} R u^{\prime}+2 x^{\prime T} N u^{\prime}\right) d t .
$$

where $Q$ and $R$ are the state and input control weighting cost square symmetric matrices, respectively. The matrices are selected by the designer depending on the relatively importance of parameters for practical control issues. Here, $Q-$ $N R^{-1} N^{T} \geq 0$, and $R>0$.

In order to obtain a better performance, $Q$ and $R$ are synthesised in a value that satisfies the controller's requirement. After determining these two values, the matrix $S$ can be determined by solving modified algebraic Riccati-equation:

$$
A^{\prime T} S+S A^{\prime}-\left(S B^{\prime}+N\right) R^{-1}\left(B^{\prime T} S+N^{T}\right)+Q=0 .
$$

The optimal state feedback gain matrix $K^{\prime}$ can be determined by:

$$
K^{\prime}=R^{-1}\left(B^{\prime T} S+N^{T}\right)
$$

where $S$ is the solution of the algebraic Riccati-equation and $N=0$. The solution of $K^{\prime}$ converse the error to zero provided the stable system and minimisation of the cost function. 


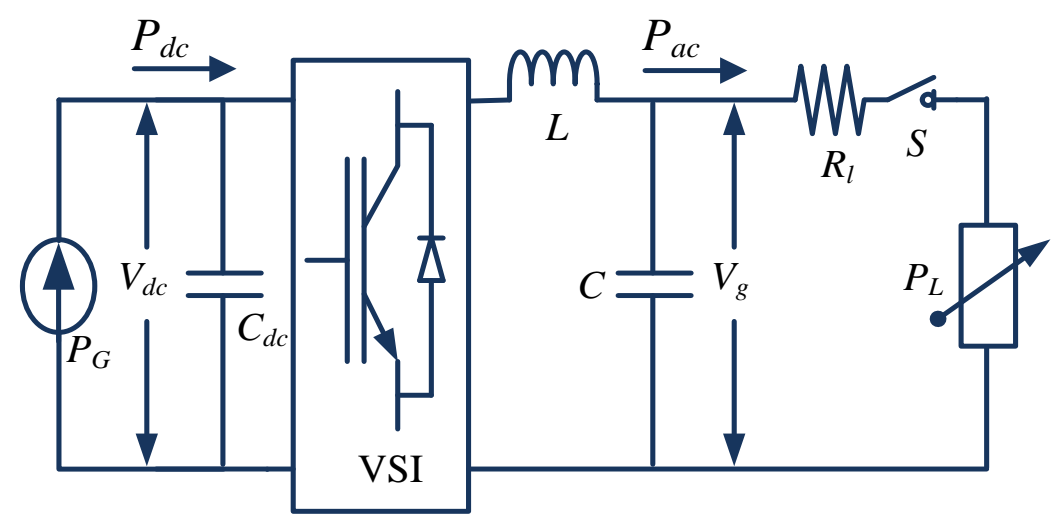

Figure 5: Simulation diagram for small microgrid system.

\section{Case Study using a Small Microgrid System}

A power source connected to a resistive network is studied first to understand the performance of the proposed controller and its advantages compared with those of the VBD controller. A lossless line $\left(R_{l}=0 \Omega\right)$ is used to determine the relationship between load power $\left(P_{L}\right)$ and $V_{d c}$, with only resistive loads connected to the terminal. The DC-link capacitor value is $1.5 \mathrm{mF}$, the predefined capacitor voltage $V_{d c}=400 \mathrm{~V}$, the carrier frequency of PWM $8 \mathrm{kHz}$, the sampling frequency $10 \mathrm{kHz}$, the value of $K_{v}$ equals 0.085 , the reference grid voltage for controlling the inverter $50 \mathrm{~Hz} 220 \mathrm{~V}$ (rms) and the filter parameters $L=2 \mathrm{mH}$ and $C=12 \mu \mathrm{F}$.

\subsection{Performance of proposed controller}

The proposed controller is employed in the VSI connected to the resistive loads illustrated in Figure 5. The DC-link voltage band is taken as 5\% of the DC-link voltage to supply and/or absorb the additional and/or reduced demand in the network [38]. In the proposed control algorithm, terminal voltage variations using the DC busbar's energy are kept to as low as possible to ensure network power quality as consumers do not expect voltage variations when a generated power increases or decreases. Although the $V_{d c}$ provides demand information directly to the network, it is not incorporated directly in the power set-point due to information missing for the autonomous load curtailment that occurs during lower than required power generation. To receive the information for load curtailment on the demand side, 


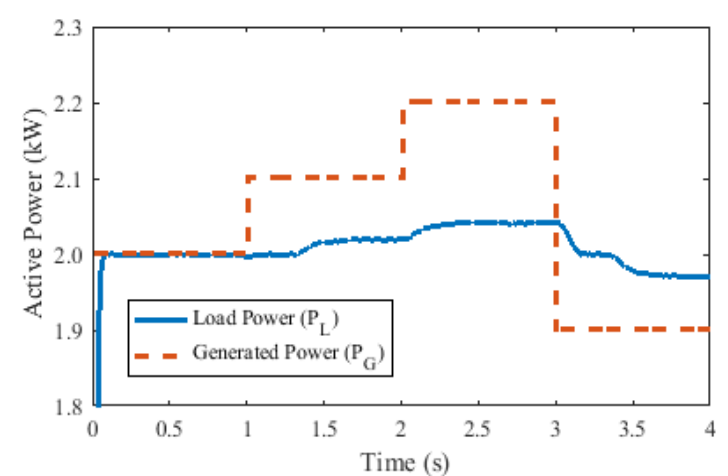

(a) $P$

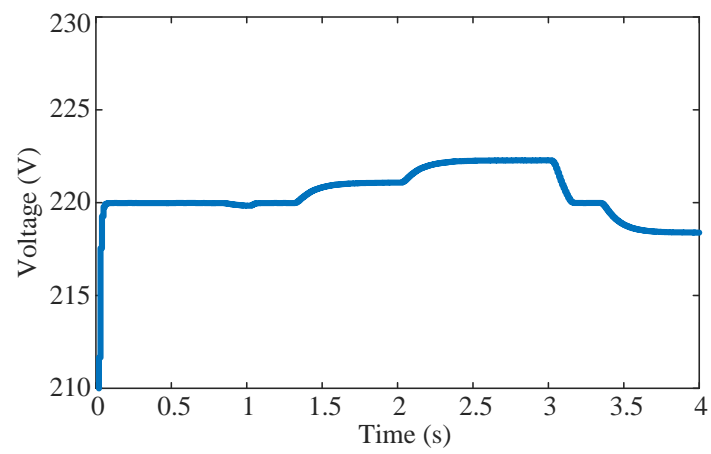

(c) $V_{g}$

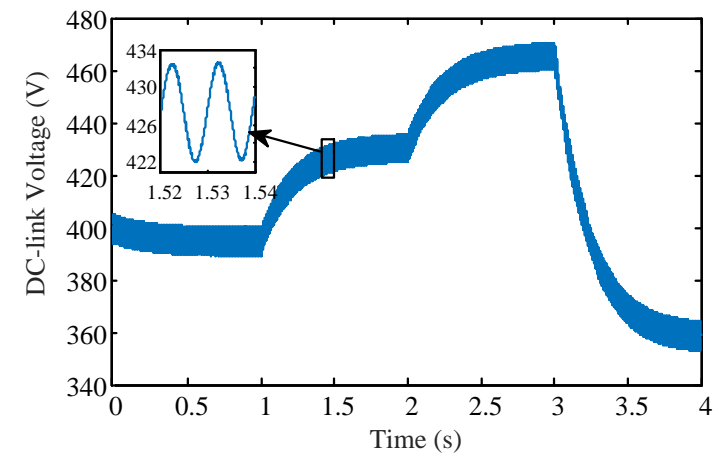

(b) $V_{d c}$

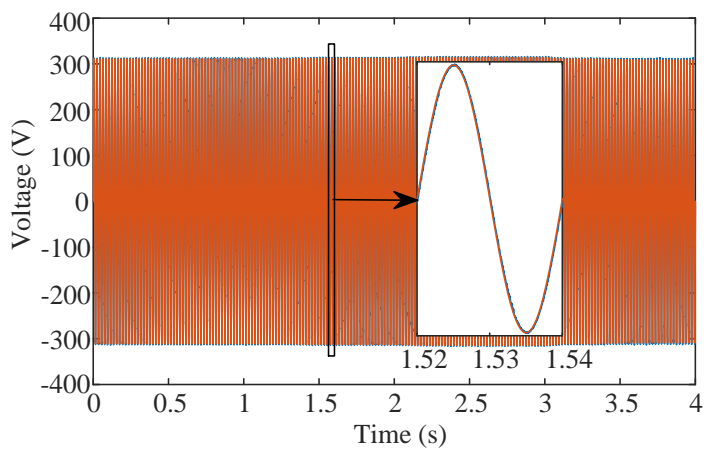

(d) $v_{g}$

Figure 6: Active power supply in network and responses of electrical quantities.

the DC-link voltage is connected to the grid voltage which is linked to the power set-point.

The purpose of this simulation is to demonstrate how dc-link voltage is related to the power generation unit $\left(P_{G}\right)$. To observe the phenomenon during input power changes, a constant resistive load of $2.0 \mathrm{~kW}$ and variable input power supply are taken into account in the load and input sides, respectively. Input power increases and decreases according to the following limits.

$$
P_{G}= \begin{cases}2.0 \mathrm{~kW} & \text { if } t<1.0 \mathrm{~s} \\ 2.1 \mathrm{~kW} & \text { if } 1.0 \mathrm{~s}<t<2.0 \mathrm{~s} \\ 2.2 \mathrm{~kW} & \text { if } 2.0 \mathrm{~s}<t<3.0 \mathrm{~s} \\ 1.9 \mathrm{~kW} & \text { if } 3.0 \mathrm{~s}<t<4.0 \mathrm{~s}\end{cases}
$$

In this simulation, a power load $\left(P_{L}\right)$ with $50 \mathrm{~Hz} 220 \mathrm{~V}(\mathrm{rms})$ and nominal DC-link voltage $\left(V_{d c}\right)$ are considered equal to $2.0 \mathrm{~kW}$ and $400 \mathrm{~V}$, respectively. In Figures $6 \mathrm{a}$ 
and $6 \mathrm{~b}$, it is observed that the power supply and power demand are similar $(2.0 \mathrm{~kW})$ upto $1.0 \mathrm{~s}$, but DC-link voltage reduces. The reasons for declining DC-link voltage are energy conversion losses which are beyond the scope of this paper. The increased power generation $(2.1 \mathrm{~kW})$ at $t=1.0 \mathrm{~s}$, which is higher than the power consumption $(2.0 \mathrm{~kW})$ in the load, is balanced by the DC-link energy during the first $0.5 \mathrm{~s}$ interval and causes the $V_{d c}$ rises to approximate $440 \mathrm{~V}$ at $t=1.5 \mathrm{~s}$. Although the power consumption load is assumed $2.0 \mathrm{~kW}$ with $50 \mathrm{~Hz} 220 \mathrm{~V}$, the power dissipation is not constant due to augmented or reduced voltage supply, which is shown in Figure 6c and related to the DC-link voltage, by the source.

When the power production increases further to $2.2 \mathrm{~kW}$, the DC-link voltage again increases to around $460 \mathrm{~V}$ indicating a clear relationship between the power generation and DC-link voltage. At $t=3.0 \mathrm{~s}$, the generated power decreases to $1.9 \mathrm{~kW}$, i.e., $2.0 \mathrm{~kW}-1.9 \mathrm{~kW}=0.1 \mathrm{~kW}$ power is shortage compared to the power consumption at load. This lack of power supply is temporarily met by the DClink energy stored previously, as shown in Figure 6b. When the $V_{d c}$ reaches the minimum and/or maximum limit, the proposed DC-link controller decreases and/or increases the grid voltage to maintain stability in the network while keeping the $V_{d c}$ within limits. In the interval between $3.4 \mathrm{~s}$ and $4.0 \mathrm{~s}$, the power drawn by the load is supposed to be $2.0 \mathrm{~kW}$ but, in fact, is less than $2.0 \mathrm{~kW}$. This is because, as the $V_{d c}$ reaches the minimum voltage limit, it causes a decreased grid voltage and, consequently, reduced power is consumed by the loads. The energy stored in the capacitor can be expressed in terms of the capacitor's voltage as:

$$
E_{d c}=\frac{1}{2} C_{d c} V_{d c}^{2}
$$

The energy can be related to the power by:

$$
E_{d c}=\int_{0}^{t} P_{d c} d t
$$

Substituting Eq. (20) into Eq. (19) and assuming a constant power supply, the mathematical relationship between the $V_{d c}$ and $P_{d c}$ can be derived as:

$$
V_{d c}=\sqrt{\frac{2 P_{d c} t}{C_{d c}}}
$$


The theoretical DC-link voltage $\left(V_{d c}\right)$ for the decreased power can be evaluated using Eq. (21). It is worth noting that the $V_{d c}$ is directly proportional to the square root of the time, that is, the voltage falls in a non-linear manner with time. Therefore, small amounts of increased/decreased power in the DC busbar for longer periods can lead to violations of the maximum/minimum predefined DC-link voltages.

It is observed in Figure 6d that the instantaneous reference grid voltage is perfectly tracked by the grid voltage and controlled by the LQI control method shown in Figure 1. It is also observed in Figure $6 \mathrm{~b}$ that the $V_{d c}$ frequency is $100 \mathrm{~Hz}$ because of the effect of the capacitor charging and discharging with the full bridge inverter.

This simulation is conducted with the application of the proposed controller for an inverter with a voltage controller, by implementing the LQI method and

\subsection{Comparative study}

In the last simulation of a simple microgrid, the proposed control strategy is compared with the VBD control approach shown in Figure 7. Power generation of the input source and consumer resistive loads vary according to the following limits.

$$
P_{G}= \begin{cases}2.0 \mathrm{~kW} & \text { if } t<1.0 \mathrm{~s} \\ 2.2 \mathrm{~kW} & \text { if } t>1.0 \mathrm{~s}\end{cases}
$$




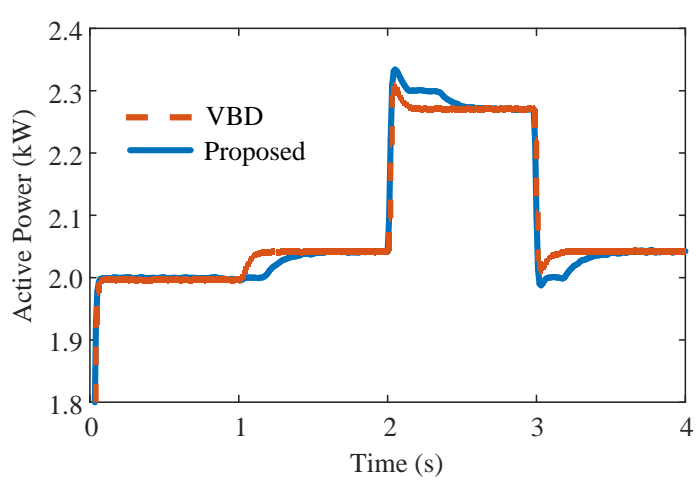

(a) $P_{L}$

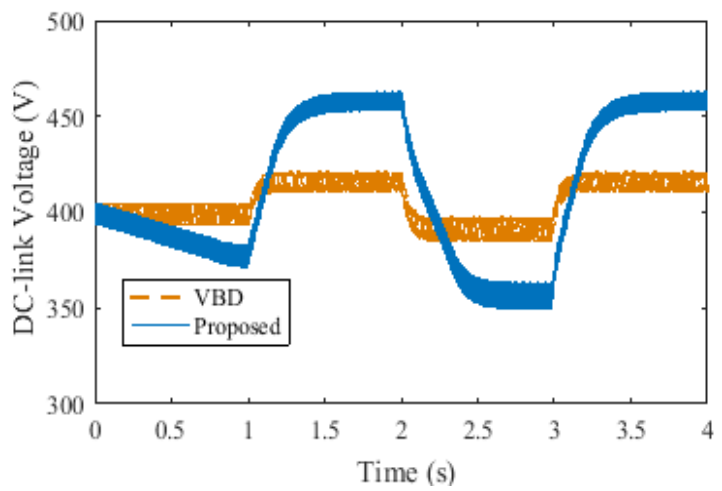

(c) $V_{d c}$

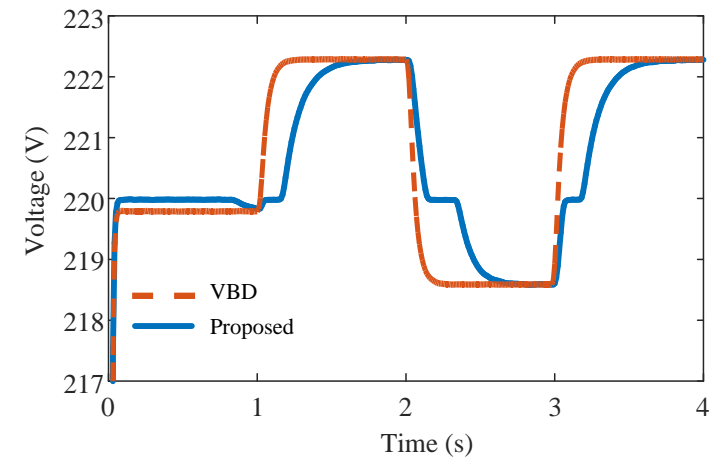

(b) $V_{g}$

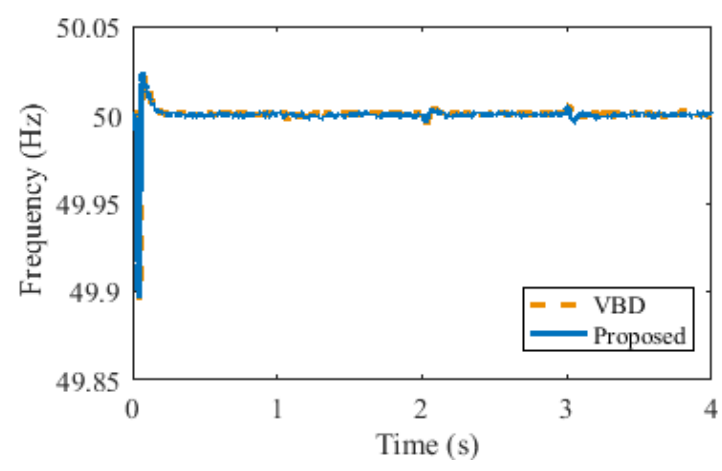

(d) $f$

Figure 7: Proposed controller performance with respect to VBD control. 
and

$$
P_{L}= \begin{cases}2.0 \mathrm{~kW} & \text { if } t<2.0 \mathrm{~s} \\ 2.3 \mathrm{~kW} & \text { if } 2.0 \mathrm{~s}<t<3.0 \mathrm{~s} \\ 2.0 \mathrm{~kW} & \text { if } t>3.0 \mathrm{~s}\end{cases}
$$

As it is shown that voltage variations are comparatively lower under the proposed controller's algorithm than that of the VBD controller, the power supply to the loads depicted in Figure 7 is justified. Note that the power demands in the network for $2.0 \mathrm{~kW}$ do not match exactly because, as the voltage supply in the network increases, a specific load's consumption is more, than its power rating. The power consumption and grid voltage relationship can be established by:

$$
P_{L}=\frac{V_{g}^{2}}{R_{t}}
$$

where $R_{t}=$ total resistance and $V_{g}=$ terminal grid voltage.

As, for a specific power and voltage rating, the resistance is constant, any change in the grid voltage is proportional to the square root of the power demand. As the voltage deviates from its nominal level of $220 \mathrm{~V}$, the corresponding power consumption in the load also deviates from its rated value; for example, a $2.0 \mathrm{~kW}$ consumption load's power rating for a nominal voltage of $220 \mathrm{~V}$ provides a $24.2 \Omega$ resistance. If the voltage increases to $222.5 \mathrm{~V}$, by applying Equation (22), the power consumption also increases to $2.04 \mathrm{~kW}$ for the $2.5 \mathrm{~V}$ surplus voltage depicted in Figure $7 \mathrm{a}$ between 1 and $2 \mathrm{~s}$. Accordingly, the other power ratings increase/decrease based on the terminal voltage across a load.

In the proposed control strategy, the terminal voltage is used as an information source for balancing the power with minimum voltage deviations from the nominal voltage. Since this strategy uses the capacitor's energy, it provides negligible voltage fluctuations during the turning on/off of the load unless the $V_{d c}$ touches the boundary. The principal advantage of this proposed control strategy is that it prevents a sudden network voltage change during the turning on of a dynamic load such as a motor which is a problem encountered by the VBD controller, as shown in Figure 7b. Generally, turning on a motor takes 3 to 12 times more current than running it and, in such a condition, the VBD controller has a direct effect on the 


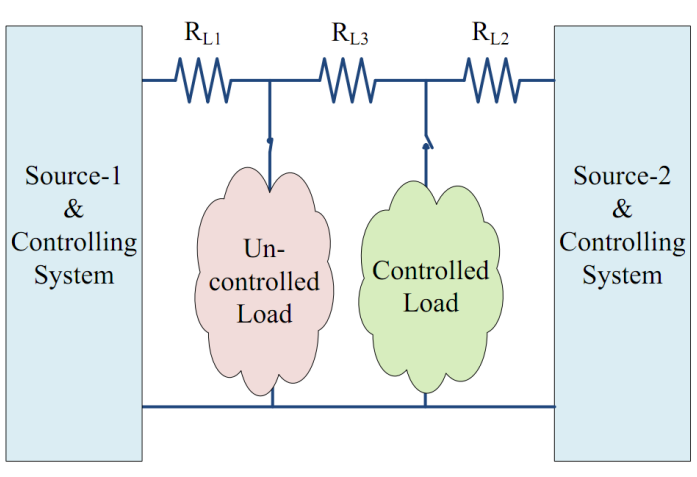

(a)

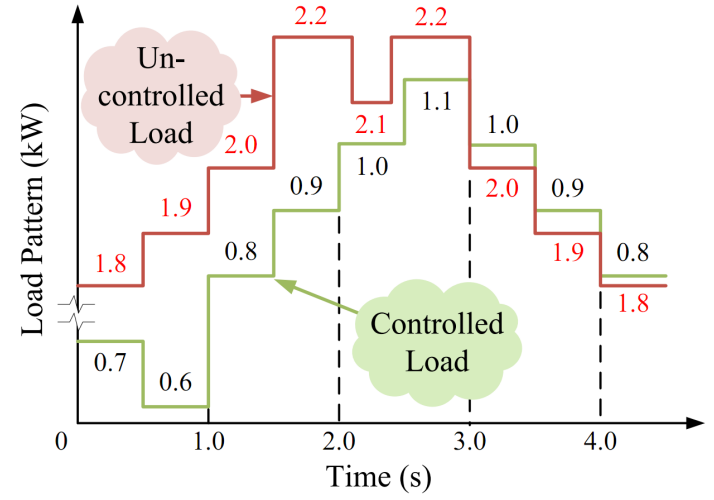

(b)

Figure 8: Simulation schemes for (a) generators and load arrangement, and (b) load participation schedule for controlled and uncontrolled loads.

network voltage whereas the proposed controller resolves this issue. It is concluded that the proposed controller introduces less variation into the terminal voltage with respect to load changes using a voltage band in the DC-link controller, as illustrated in Figures $7 \mathrm{~b}$ and $7 \mathrm{c}$. Also, the frequency experiences no major change in the connecting/disconnecting load for a constant frequency set-point, as shown in Fig. $7 \mathrm{~d}$.

\section{Microgrid with Multiple Generators}

This section discusses the proposed control strategy used to control multiple DG units and manage the demand dispatch during a power scarcity in a network by

implementing a relay operating function at the terminals of the controlled loads.

\subsection{Balanced power generation}

This simulation considers a realistic microgrid in which two power generators, a dispatchable/gas generator and renewable source, supply power to both critical loads (a hospital and paper industry) and non-critical ones (a lighting load, heating system in a house, boilers and an energy storage system), as shown in Figure 8a. DG-1 is arranged with a dispatchable power supply control strategy, the nominal power set-point of which equals $2.0 \mathrm{~kW}$. Generally, as this set-point is selected by the supervisory control system based on the network's scheduled power, e.g., its load 
prediction, it changes over time. The $P_{d c}$ depends greatly on the unit's capacity to obtain its optimum operating point. A renewable energy source, such as solar, and energy storage features, which are assumed to supply $0.8 \mathrm{~kW}$ of constant power, are adopted for DG-2 to inject power into the network. As solar power generation varies during a day, its assumed characteristics are varied similar to those of a $24 \mathrm{~h}$ day (with a shortened time scale in this simulation), and the DG-2's power production limits given as

$$
P_{G 2}= \begin{cases}0.8 \mathrm{~kW} & \text { if } t<1.0 \mathrm{~s} \\ 1.0 \mathrm{~kW} & \text { if } 1.0 \mathrm{~s}<t<2.0 \mathrm{~s} \\ 1.2 \mathrm{~kW} & \text { if } 2.0 \mathrm{~s}<t<3.0 \mathrm{~s} \\ 1.0 \mathrm{~kW} & \text { if } 3.0 \mathrm{~s}<t<4.0 \mathrm{~s} \\ 0.8 \mathrm{~kW} & \text { if } 4.0 \mathrm{~s}<t<4.5 \mathrm{~s} .\end{cases}
$$

Note that the term "distributed generator (DG)" indicates an inverter and DG power generation its input values.

This simulation uses two types of network loads: (1) uncontrolled; and (2) controlled. In the former, such as a hospital, the constant power supply with uninterrupted delivery required to prevent huge losses. Considering the particular features of an uncontrolled load, its pattern is shown in Figure 8b. In a controlled load, such as lighting in houses, the power supply can be disrupted for a short time during deficit power generation. This situation may happen due to unavailable renewable resources, e.g., less power production under cloudy skies and less wind velocity for solar and wind generators, respectively. The controlled load pattern shown in Figure $8 \mathrm{~b}$ is adopted from a general residential power consumption rate. The different line resistances $\left(R_{L 1}=0.3 \Omega, R_{L 2}=0.5 \Omega\right.$ and $\left.R_{L 3}=0.2 \Omega\right)$ are chosen for this simulation as they depend on the DGs' installation and load distances. Generally, a generator's capacity is selected to meet the power demand and its variations, an assumption discussed in this section.

The objective of this study is to demonstrate how, by applying the proposed controller, the two sources can meet the power demand of both controlled and uncontrolled loads in a network. The excess and deficit power information can be 


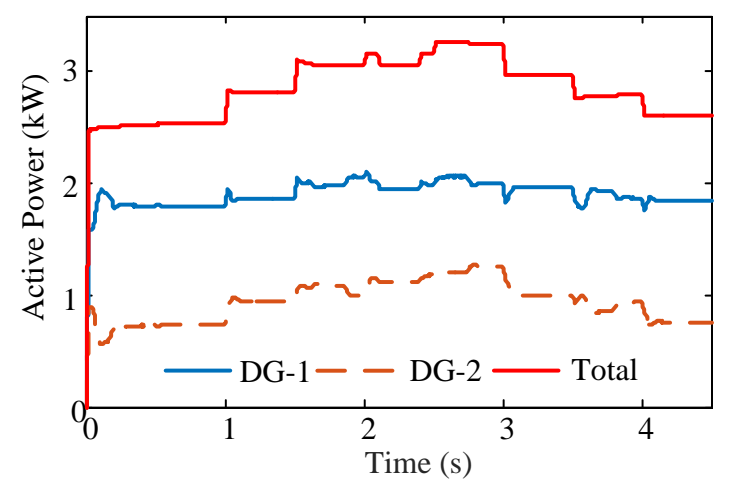

(a) $P_{L}$

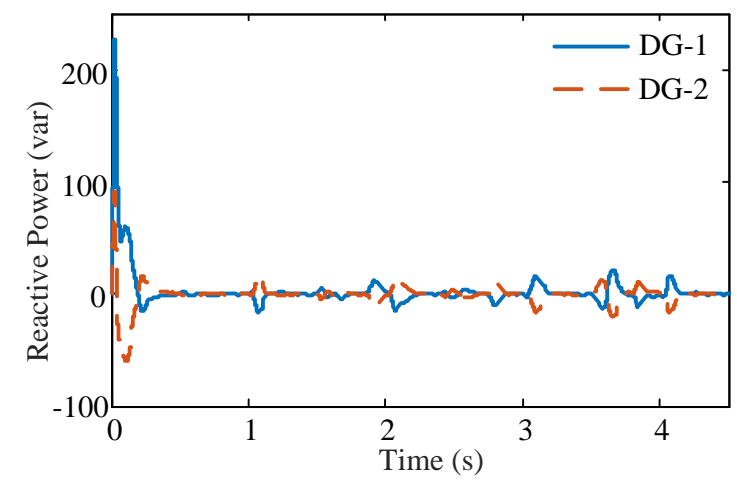

(c) $Q$

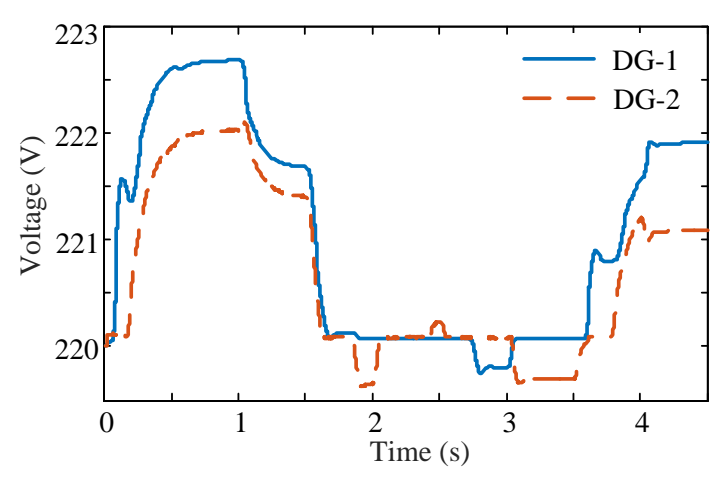

(b) $V_{g}$

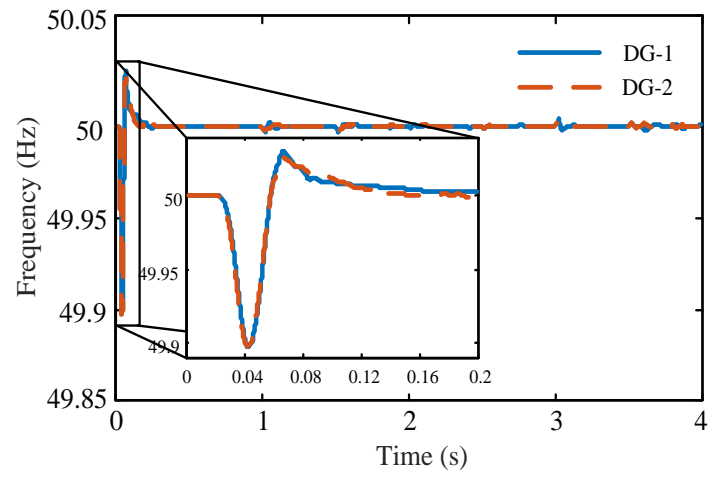

(d) $f$

Figure 9: Balanced power generation: participation of controlled and uncontrolled loads in network. 


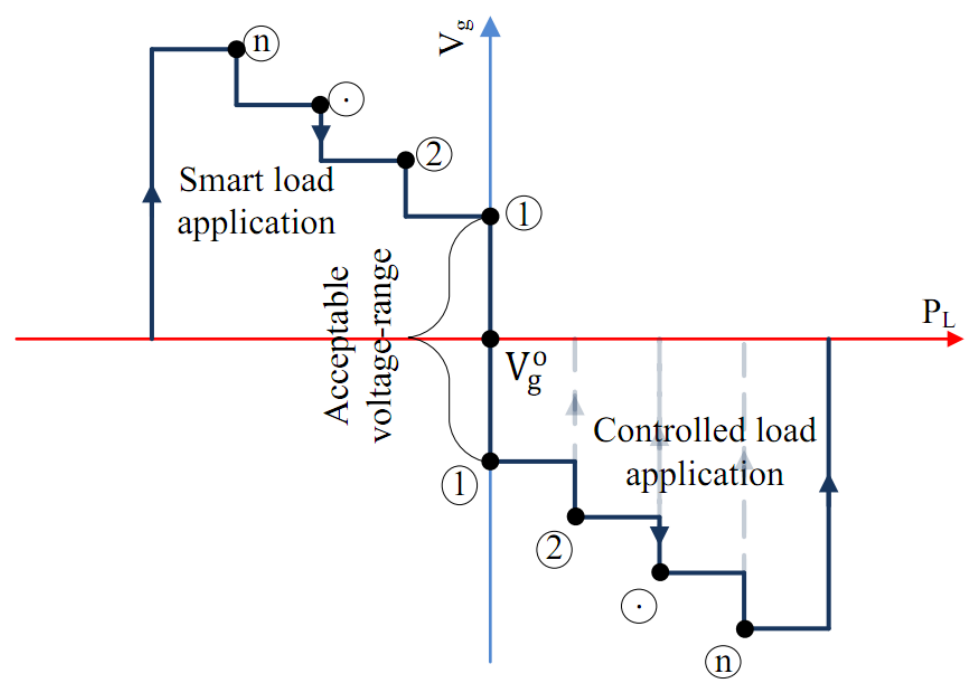

Figure 10: Relay implementation scheme in distribution network. a stable voltage between $t=2$ and $3 \mathrm{~s}$ due to the capacitor's energy. Therefore, it can be concluded that using an energy storage system in the DC busbar can ensure a stable voltage supply to customer premises. In practice, the power generator's 
capacity is sufficiently large to prevent any fluctuation in the grid voltage due to the small power demand changes in the network. As the capacitor stores energy on a temporary basis, instead of using only its own energy, if battery energy is added, stable voltage in customers premises can be ensured.

In summary, during the availability of renewable sources, the increased power supplied by DG-2 using the proposed control strategy can be properly used while an energy storage element is responsible for providing stable voltage in the network. Moreover, it is shown that the proper selection of the generator's capacity can provide uninterrupted power for both controlled and uncontrolled loads, and ensure stable voltage profiles at customer terminals.

\subsection{Decreasing power generation}

Traditionally, load curtailments for demand management are performed based on the global frequency response, which requires communication lines for monitoring frequency status and controlling loads. This process is unlike the voltage-based demand side management performed by a relay function at the specific nodes of the load points. In this study, we propose the idea of a priority list for central coordination of the entire microgrid as a primary load shedding shown in Figure 10. The priority can be enlisted according to the load distance from the supply points, types of loads, the status of a customer and economic contributions to the society, cost for loss of service and other factors. This list will be used to select the load curtailment voltage profile of customer nodes. For example, if a customer is given the least priority, then the first load curtailment will be imposed while voltage just crosses $217 \mathrm{~V}$ limit for $220 \mathrm{~V}$ nominal value. However, for the top priority customer, the voltage profile of the relay function will be selected at $209 \mathrm{~V}$ assuming $5 \%$ variation. In this way, a primary load curtailment can be performed centrally and the sole dependence on a centralised loop that uses expensive communication lines can be avoided for load demand management.

In the study, the power supply should be available for at least critical/uncontrolled loads while non-critical/controlled ones are connected to and/or disconnected from the network based on the power supply available from unpredictable renewable 


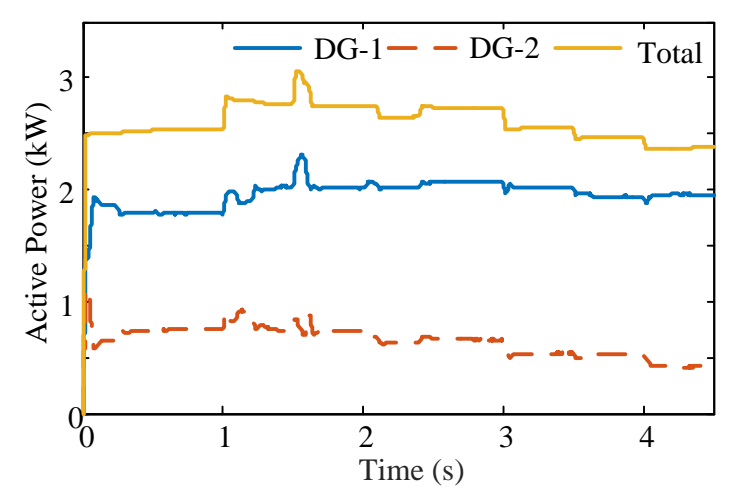

(a) $P_{L}$

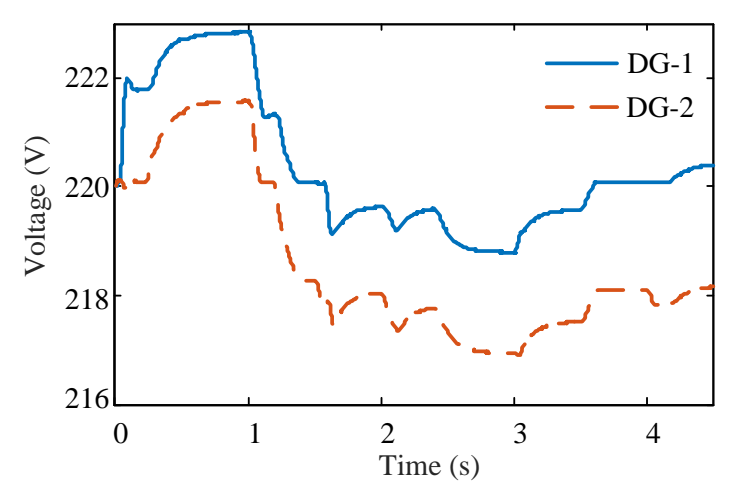

(b) $V_{g}$

Figure 11: Reducing power generation: controlled load with relay function.

sources. The terminal voltage is used as a controlling parameter in an LV network and its status indicates any excess and/or lack of power. Based on its status, load curtailment is performed by a relay to sustain stability in the network during deficit power generation.

Since there is less power generation, the only one way to balance the network power is through load control. Therefore, a relay-based grid voltage control is proposed for load curtailment to maintain stability during deficit power generation by renewable sources. For load curtailment, if the voltage goes below a certain value, a relay automatically first disconnects the least priority non-critical load. On the other hand, if it increases and exceeds a certain limit of the $V_{d c}$, an autonomous control strategy reduces the power generation set-point.

This relay operation is performed for certain load types in a network and its set-points for load curtailment, which are selected from the customer priority list, are marked as $1,2, \ldots . n$ in Figure 10, with these points indicating a sequential relay operation during deficit power generation. Although a smart load application has been shown in a relay operation, to maintain system stability, only normal loads are taken into account for this study.

This simulation is performed assuming that the power demand is satisfied from the stored energy elements, as on a rainy day, and the power decreases in the fol- 


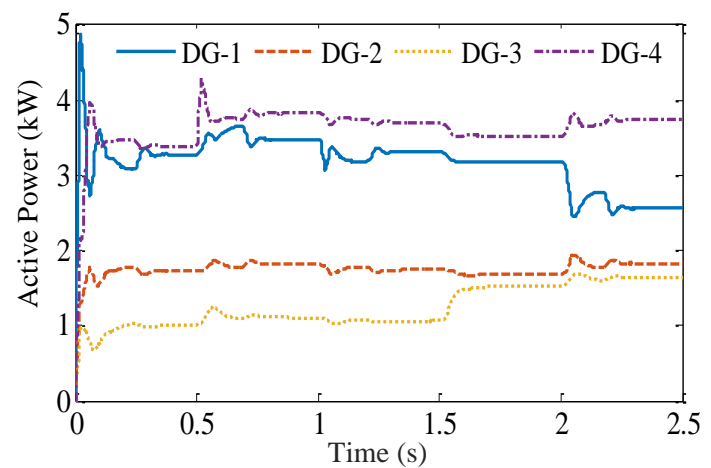

(a) $P_{L}$

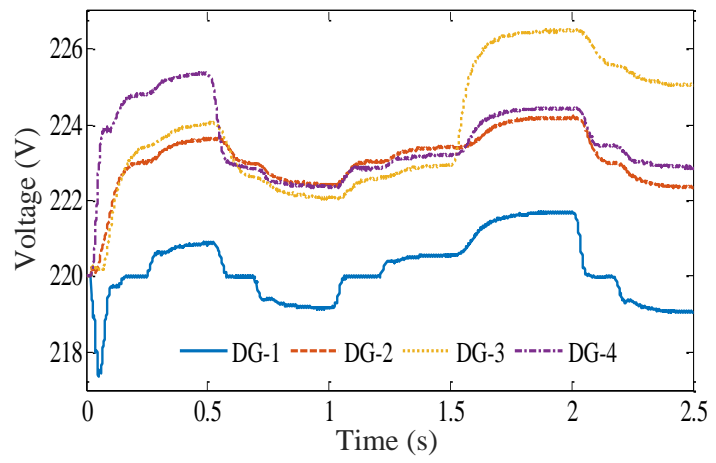

(b) $V_{g}$

Figure 12: Four generators supplying power in 16-node network.

lowing steps.

$$
P_{G 2}= \begin{cases}0.8 \mathrm{~kW} & \text { if } t<1.0 \mathrm{~s} \\ 0.7 \mathrm{~kW} & \text { if } 1.0 \mathrm{~s}<t<2.0 \mathrm{~s} \\ 0.6 \mathrm{~kW} & \text { if } 2.0 \mathrm{~s}<t<3.0 \mathrm{~s} \\ 0.5 \mathrm{~kW} & \text { if } 3.0 \mathrm{~s}<t<4.0 \mathrm{~s} \\ 0.4 \mathrm{~kW} & \text { if } 4.0 \mathrm{~s}<t<4.5 \mathrm{~s} .\end{cases}
$$

In the relay operation scheme shown in Figure 10, the network's lower voltage limit decreases gradually based on the position of the load and customer priority list. In this simulation, the controlled loads are accumulated by a $0.1 \mathrm{~kW}$ rating, with each equipped with a relay function, the values of which are separated by $0.1 \mathrm{~V}$ after $217 \mathrm{~V}$ for the first relay operation. The results for decreasing power are shown in Figure 11 in which it is clear that the decreasing terminal voltage below a defined value of $217 \mathrm{~V}$ for the first load at $t=1.65 \mathrm{~s}$ detaches the load from the network to maintain voltage stability. Also, in Figure 11b, it is observed that the first load disconnection improves the voltage profile; but the decreased power generation (from $0.7 \mathrm{~kW}$ to $0.6 \mathrm{~kW}$ ) at $t=2 \mathrm{~s}$ leads to a decreased DG-2 terminal voltage that is then balanced by a load cut-off of $0.1 \mathrm{~kW}$ at $t=2.13 \mathrm{~s}$. This approach boosts the terminal voltage on a temporary basis because of the uncontrolled load participating in the network. Note that the defined relay operational values and DG units terminal values are not the same due to the resistance between the units and lines. 


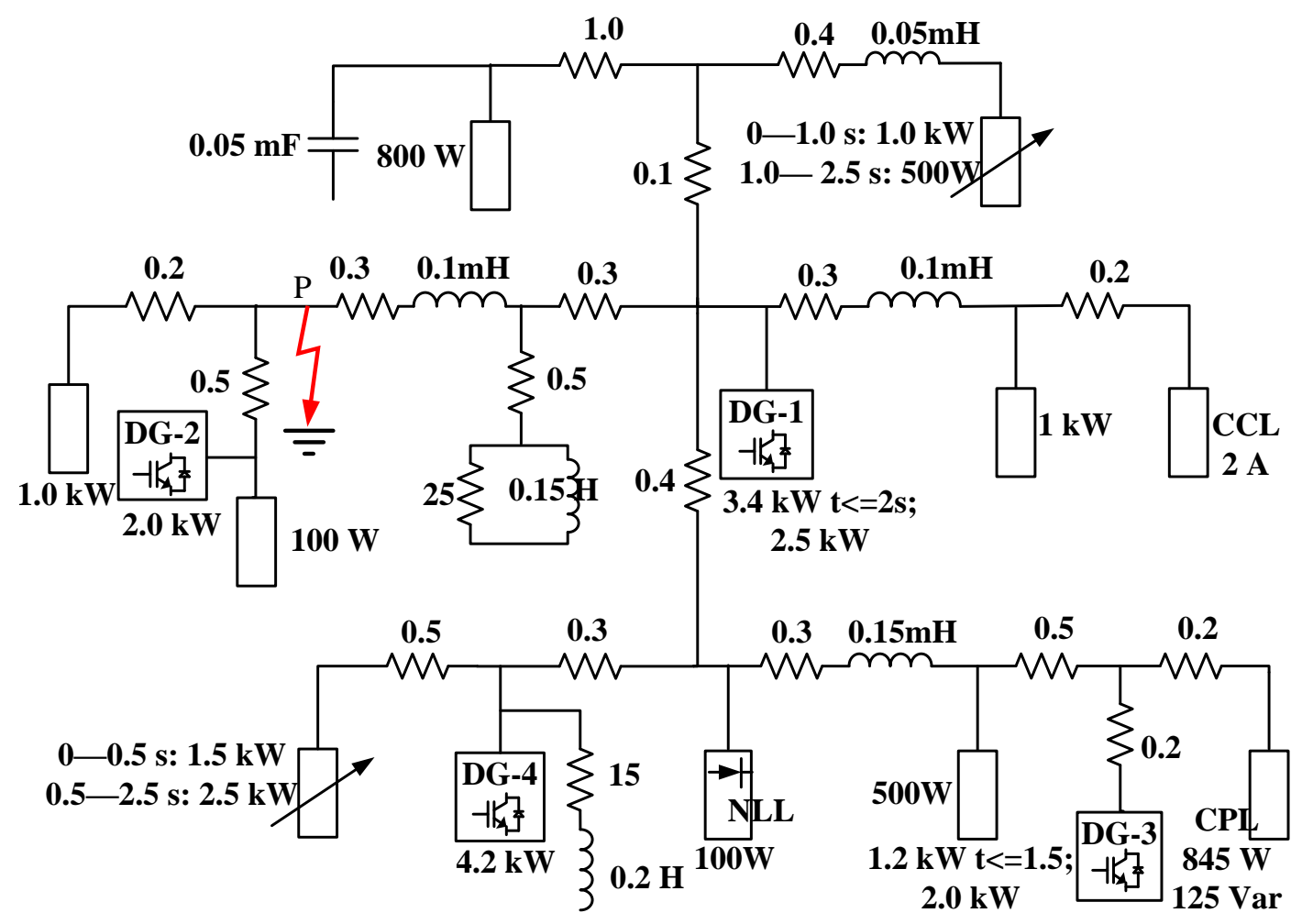

Figure 13: Modified 16-node test feeder.

In this simulation, a relay-based load curtailment for an autonomous load-side management is presented. This approach is suitable for primary load control management without depending on communication lines and can enhance the reliability of a microgrid with communication lines.

\subsection{Case study}

The test feeders considered for the application of the proposed control strategy are depicted in Figure 13. The test feeder suitably arranged as an LV microgrid provides higher resistive transmission lines than inductive ones. The purpose of this simulation is to demonstrate the influence of load and generation output changes, and the connections of various loads, i.e., constant current (CCL), non-linear (NLL), constant power (CPL) and dynamic. In this study, four DG units, two dynamic and two static, are connected to provide power to the network and all are equipped with the proposed VBD controller which has a voltage band of $5 \%$ of that DC-link voltage. 


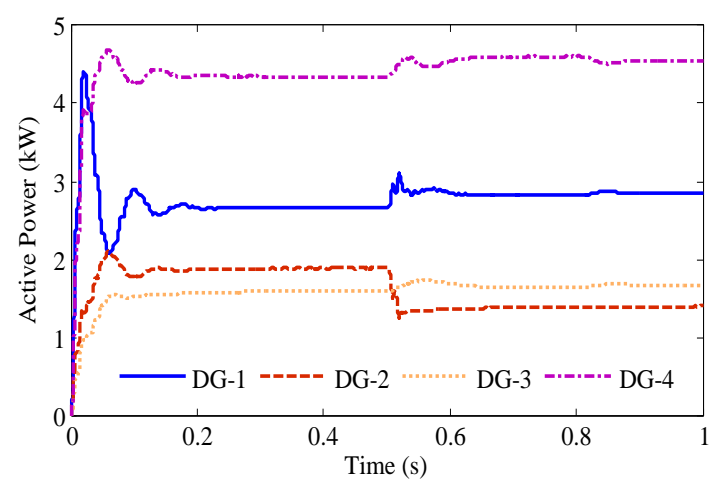

(a) $P_{L}$

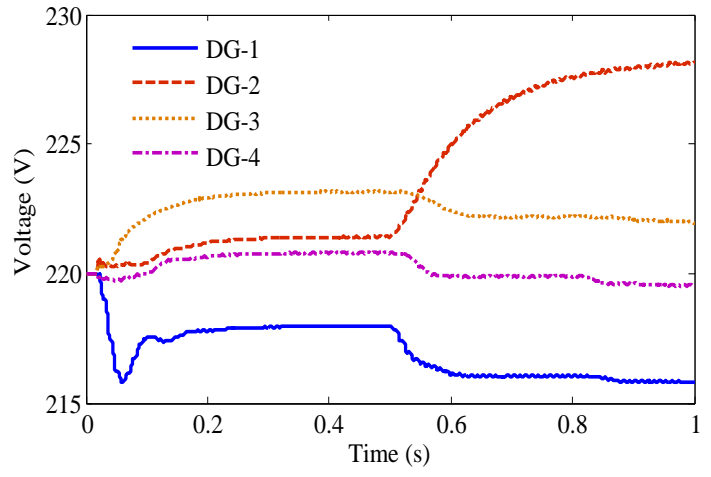

(b) $V_{g}$

Figure 14: Four generators supplying power during fault.

To observe a load variation effect and coordination among the controllers, changes are made to the two dynamic loads incorporated in this network as shown in Figure 13. Although the load is changed at $t=0.5 \mathrm{~s}$ near DG-4 from $1.5 \mathrm{~kW}$ to $2.0 \mathrm{~kW}$ which is picked up mainly by DG-4, other generators also contribute to this, as shown in Figure 12a. As all generators participate in the increased power demand, their terminal voltages decrease between $0.5<t<1 \mathrm{~s}$, as shown in Figure $12 \mathrm{~b}$, The influence of decreasing power consumption is shown at $t=1 \mathrm{~s}$ by changing the second dynamic load from $1.0 \mathrm{~kW}$ to $0.5 \mathrm{~kW}$ near DG-1, a power change that is clearer at DG-1 than at the other generators. Any load change in the network is first shared by the nearest DG units although the others also participate.

After load changes in the network, DG power variations, which are a common scenario for renewable sources, are demonstrated at $t=1.5 \mathrm{~s}$ and $t=2 \mathrm{~s}$ in DGs-3 and -1 , respectively. It is observed that, at $t=1.5 \mathrm{~s}, \mathrm{DG}-3$ injects more power into the network while the other generators reduce their power production to balance the system. On the other hand, the power production of DG- 1 , which reduces at $t=2 \mathrm{~s}$, is compensated by the other generators, as shown in Figure 12a.

Furthermore, the effectiveness of the controller proposed is measured after introducing a fault at point $\mathrm{P}$ at $t=0.5 \mathrm{~s}$, as a result, a circuit breaker disconnects DG-2 from the rest of the network with some local loads. From Figures $14 \mathrm{a}$ and $14 \mathrm{~b}$, it is observed that DG-2 reduces its power delivery by increasing terminal voltage and other DGs supply more power by decreasing terminal voltage to cover additional 


\section{Acknowledgment}

M. A. Hossain would like to thank Walid Issa, Sheffield Hallam University, for his valuable knowledge exchange for the paper, and we thank the anonymous reviewers for their so-called insightful comments. In addition, M. A. Hossain would 
like to acknowledge the supports of this research received from The Dhaka Univer-

sity of Engineering \& Technology (DUET) and The University of New South Wales (UNSW).

\section{References}

[1] L. Gelažanskas, A. Baranauskas, K. A. Gamage, M. Ažubalis, Hybrid wind power balance control strategy using thermal power, hydro power and flow batteries, Int Journal of Elec. Power \& Energy Syst. 74 (Jan. 2016) 310-321.

[2] X. Tan, Q. Li, H. Wang, Advances and trends of energy storage technology in microgrid, Int Journal of Elec. Power \& Energy Syst. 44 (1) (Jan. 2013) $179-191$.

[3] A. D. Rathnayaka, V. M. Potdar, T. Dillon, S. Kuruppu, Framework to manage multiple goals in community-based energy sharing network in smart grid, Int Journal of Elec. Power \& Energy Syst. 73 (Dec. 2015) 615-624.

[4] R. H. Lasseter, P. Paigi, Microgrid: a conceptual solution, in: Proc. IEEE Power Electron. Spec. Conf., Aachen, Germany, Vol. 6, Jun. 2004, pp. 4285-4290.

[5] M. A. Hossain, H. R. Pota, A. M. O. Haruni, M. J. Hossain, Dc-link voltage regulation of inverters to enhance microgrid stability during network contingencies, Elect. Power Syst. Res. 147 (Jun. 2017) 233-244.

[6] M. A. Hossain, H. R. Pota, W. Issa, M. J. Hossain, Overview of ac microgrid controls with inverter-interfaced generations, Energies 10 (9) (2017) 1300.

[7] F. Petrakopoulou, On the economics of stand-alone renewable hybrid power plants in remote regions, Energy Convers Manage 118 (Jun. 2016) 63-74.

[8] T. Alnejaili, S. Drid, D. Mehdi, L. Chrifi-Alaoui, R. Belarbi, A. Hamdouni, Dynamic control and advanced load management of a stand-alone hybrid renewable power system for remote housing, Energy Convers Manage 105 (Nov. 2015) 377-392. 
[9] S. Barsali, M. Ceraolo, P. Pelacchi, D. Poli, Control techniques of dispersed generators to improve the continuity of electricity supply, in: Proc. IEEE Power Engineering Soc. Winter Meeting, Vol. 2, 2002, pp. 789-794.

[10] T. Green, M. Prodanovi, Control of inverter-based micro-grids, Elect. Power Syst. Res. 77 (9) (Jul. 2007) 1204-1213.

490

495

[17] J. He, Y. W. Li, J. M. Guerrero, F. Blaabjerg, J. C. Vasquez, An islanding microgrid power sharing approach using enhanced virtual impedance control scheme, IEEE Trans. Power Electron. 28 (11) (Nov. 2013) 5272-5282.

[18] A. Engler, N. Soultanis, Droop control in LV-grids, in: Proc. Int. Conf. Future islanded microgrid, Int. Journal of Renew. Energy Research (IJRER) 5 (3) (Jul. 2015) 806-814.

[12] N. Bizon, M. Oproescu, M. Raceanu, Efficient energy control strategies for a standalone renewable/fuel cell hybrid power source, Energy Convers Manage 90 (Jan. 2015) 93-110.

[13] F. Katiraei, R. Iravani, N. Hatziargyriou, A. Dimeas, Microgrids management, IEEE Power Energy Mag. 6 (3) (May-June 2008) 54-65.

[14] H. R. Pota, M. J. Hossain, M. Mahmud, R. Gadh, Control for microgrids with inverter connected renewable energy resources, in: Proc. IEEE PES General Meeting- Conf. \& Expo., Jul. 2014, pp. 1-5.

[15] Q.-C. Zhong, Robust droop controller for accurate proportional load sharing among inverters operated in parallel, IEEE Trans. Ind. Electron. 60 (4) (Apr. 2013) 1281-1290.

[16] Q.-C. Zhong, Y. Zeng, Universal droop control of inverters with different types of output impedance, IEEE Access 4 (Jan. 2016) 702-712.

Power Syst., IEEE, Nov. 2005, pp. 6-pp.

[11] M. A. Hossain, H. R. Pota, Voltage tracking of a single-phase inverter in an 
[19] C. K. Sao, P. W. Lehn, Control and power management of converter fed microgrids, IEEE Trans. Power Syst. 23 (3) (Aug. 2008) 1088-1098.

[20] X. Yu, A. M. Khambadkone, H. Wang, S. T. S. Terence, Control of parallelconnected power converters for low-voltage microgrid - part i: A hybrid control architecture, IEEE Trans. Power Electron. 25 (12) (Dec. 2010) 2962-2970.

[21] M. H. Moradi, M. Eskandari, S. M. Hosseinian, Cooperative control strategy of energy storage systems and micro sources for stabilizing microgrids in different operation modes, Int Journal of Elec. Power \& Energy Syst. 78 (Jun. 2016) 390-400.

[22] T. L. Vandoorn, J. D. De Kooning, B. Meersman, B. Zwaenepoel, Control of storage elements in an islanded microgrid with voltage-based control of DG units and loads, Int. Journal of Elec. Power \& Energy Syst. 64 (Jan. 2015) 996-1006.

[23] T. L. Vandoorn, B. Meersman, L. Degroote, B. Renders, L. Vandevelde, A control strategy for islanded microgrids with dc-link voltage control, IEEE Trans. Power Del. 26 (2) (Apr. 2011) 703-713.

[24] Q. Shafiee, J. M. Guerrero, J. C. Vasquez, Distributed secondary control for islanded microgrids - a novel approach, IEEE Trans. Power Electron. 29 (2) (Feb. 2014) 1018-1031.

[25] L. Meng, A. Luna, E. R. Diaz, B. Sun, T. Dragicevic, M. Savaghebi, J. C. Vasquez, J. M. Guerrero, M. Graells, F. Andrade, Flexible system integration and advanced hierarchical control architectures in the microgrid research laboratory of aalborg university, IEEE Trans. Ind. Appl. 52 (2) (Mar. 2016) $1736-1749$.

[26] L. Zhang, N. Gari, L. V. Hmurcik, Energy management in a microgrid with distributed energy resources, Energy Convers Manage 78 (Nov. 2013) 297-305.

[27] D. E. Olivares, C. A. Cañizares, M. Kazerani, A centralized energy management 
system for isolated microgrids, IEEE Trans. Smart Grid 5 (4) (Jul. 2014) 18641875.

[35] B. P. Bhattarai, B. Bak-Jensen, P. Mahat, J. R. Pillai, Voltage controlled dynamic demand response, in: Proc. IEEE PES Inn. Smart Grid Tech. Conf. Europe, 2013, pp. 1-5. 
[36] B. Bhattarai, K. Kouzelis, I. Mendaza, B. Bak-Jensen, J. Pillai, K. Myers, Smart grid constraint violation management for balancing and regulating purposes, IEEE Trans. Ind. Inf. PP (99) (Mar. 2017) 1-1.

[37] M. A. Hossain, M. I. Azim, M. A. Mahmud, H. R. Pota, Active power control in an islanded microgrid using de link voltage status, in: IEEE PES Innov Smart Grid Tech Conf (ISGT) Asia: Nov 2015, pp. 1-6.

[38] M. S. Rahman, M. Hossain, J. Lu, Coordinated control of three-phase ac and dc type ev-esss for efficient hybrid microgrid operations, Energy Conversion and Management 122 (2016) 488-503. 